\title{
Las publicaciones de la Asociación Colombiana de Endocrinología, Diabetes y Metabolismo
}

\section{Enrique Ardila}

Editor Revista ACE.

Fecha de recepción: 9/06/2017

Fecha de aceptación: 28/06/2017

$\mathrm{L}$ a Asociación Colombiana de Endocrinología, Diabetes y Metabolismo, continuando con su labor misional de garantizar educación médica continua tanto para los endocrinólogos del país como para los médicos de otras especialidades, médicos generales y otros profesionales de la salud, acaba de publicar el libro FISIOLOGÍA ENDOCRINA, dirigido por el doctor Alfredo Jácome, con la colaboración en su parte editorial de los doctores Enrique Ardila y Luz Angela Casas y la participación de miembros de nuestra asociación, sobre temas relevantes de la endocrinología contemporánea . Este libro llega ya a su cuarta edición y ha sido publicado por la editorial MANUAL MODERNO.

Esta publicación está dirigida tanto a médicos endocrinólogos, como de otras especialidades médicas y médicos generales e investigadores en ciencias básicas; así mismo, deberá servir de texto de consulta para estudiantes de ciencias de la salud.

Las personas interesadas en adquirirlo se pueden dirigir a nuestra asociación o contactar directamente la editorial.

Otra publicación que vale la pena destacar son los FASCÍCULOS DE ENDOCRINOLOGÍA, los cuales llegan a su segunda edición, con temas importantes de la especialidad dirigidos a médicos internistas y generales, en aspectos relevantes como la diabetes, la obesidad, la osteoporosis, urgencias en endocrinología, la tiroides $y$, en esta nueva edición, se adicionó el tema de la endocrinología ginecológi- ca, además que dentro del fascículo de obesidad se incluyeron los aspectos psicológicos de esta entidad.

En esta publicación participaron miembros de nuestra asociación; los temas fueron tratados haciendo énfasis en sus aspectos prácticos, pero teniendo en cuenta siempre su evidencia científica.

Estos fascículos serán distribuidos en forma gratuita, tanto a los miembros de la ACE como a un grupo de médicos líderes; internistas y generales.

Esta última publicación se realizó gracias a la colaboración de los laboratorios Pfizer.

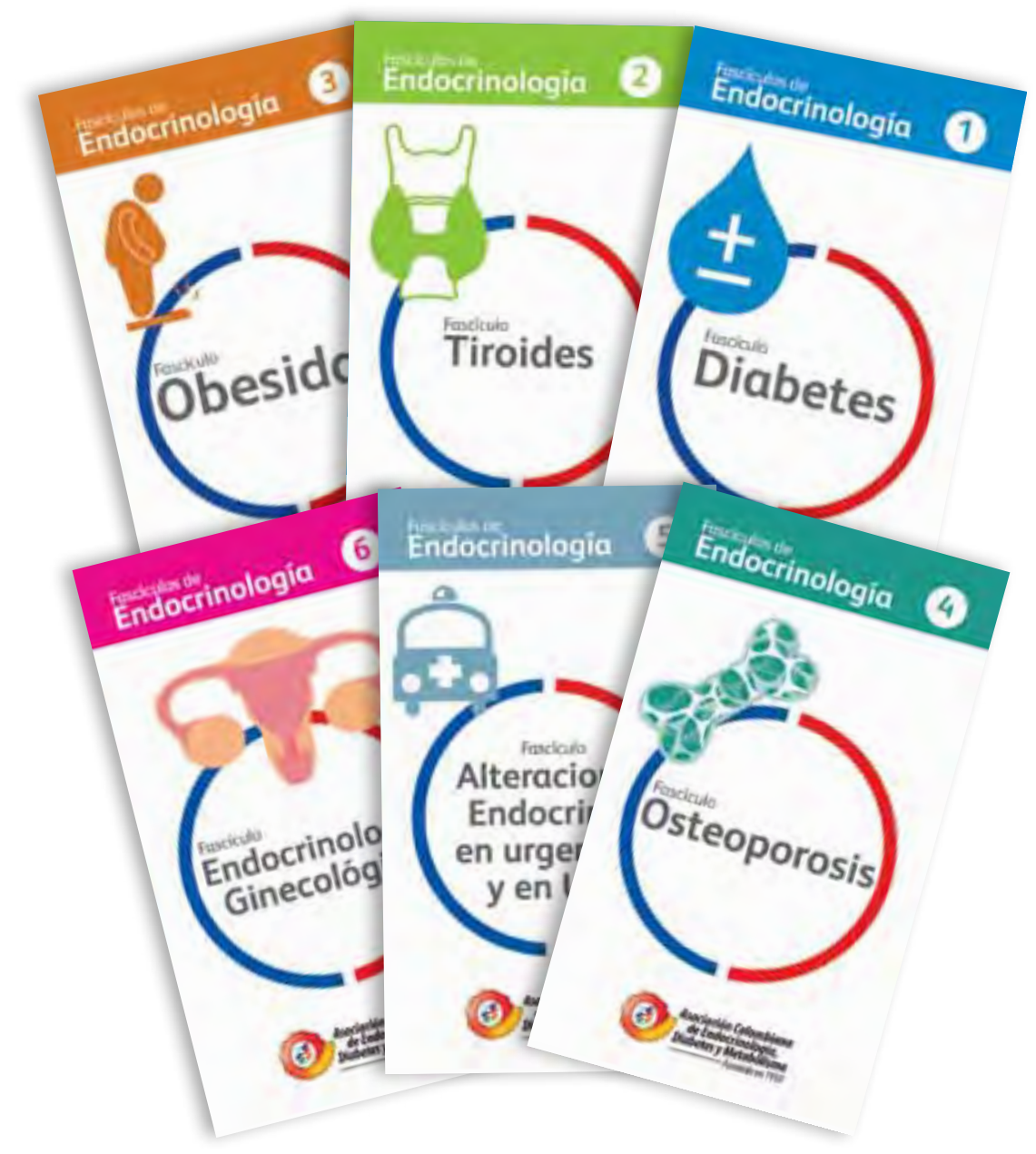

